\title{
Intact Human Ceruloplasmin Oxidatively Modifies Low Density Lipoprotein
}

\author{
Eduardo Ehrenwald, Guy M. Chisolm, and Paul L. Fox \\ Department of Cell Biology, Cleveland Clinic Research Institute, Cleveland, Ohio 44195
}

\begin{abstract}
Ceruloplasmin is a plasma protein that carries most of the copper found in the blood. Although its elevation after inflammation and trauma has led to its classification as an acute phase protein, its physiological role is uncertain. A frequently reported activity of ceruloplasmin is its ability to suppress oxidation of lipids. In light of the intense recent interest in the oxidation of plasma LDL, we investigated the effects of ceruloplasmin on the oxidation of this lipoprotein. In contrast to our expectations, highly purified, undegraded human ceruloplasmin enhanced rather than suppressed copper ion-mediated oxidation of LDL. Ceruloplasmin increased the oxidative modification of LDL as measured by thiobarbituric acid-reacting substances by at least 25 -fold in $20 \mathrm{~h}$, and increased electrophoretic mobility, conjugated dienes, and total lipid peroxides. In contrast, ceruloplasmin that was degraded to a complex containing 115- and 19-kD fragments inhibited cupric ion oxidation of LDL, as did commercial preparations, which were also degraded. However, the antioxidant capability of degraded ceruloplasmin in this system was similar to that of other proteins, including albumin. The copper in ceruloplasmin responsible for oxidant activity was not removed by ultrafiltration, indicating a tight association. Treatment of ceruloplasmin with Chelex-100 removed one of seven copper atoms per molecule and completely blocked oxidant activity. Restoration of the copper to ceruloplasmin also restored oxidant activity. These data indicate that ceruloplasmin, depending on the integrity of its structure and its bound copper, can exert a potent oxidant rather than antioxidant action on LDL. Our results invite speculation that ceruloplasmin may be in part responsible for oxidation of LDL in blood or in the arterial wall and may thus have a physiological role that is quite distinct from what is commonly believed. (J. Clin. Invest. 1994. 93:1493-1501.) Key words: ceruloplasmin • copper • oxidized LDL • oxidants • metalloproteinases
\end{abstract}

\section{Introduction}

Ceruloplasmin is an abundant plasma protein that carries $\sim 95 \%$ of the total circulating copper. It is a monomer of 132 $\mathrm{kD}$ composed almost entirely of three $42-45-\mathrm{kD}$ domains that are highly homologous to each other (1) and to the three do-

A portion of this work has appeared in abstract form (1993. Circulation. 88:180. [Abstr.]).

Address correspondence to Dr. Paul L. Fox, Department of Cell Biology, Cleveland Clinic Research Institute, NC10, 9500 Euclid Avenue, Cleveland, $\mathrm{OH} 44195$.

Received for publication 30 August 1993 and in revised form 17 November 1993.

J. Clin. Invest.

(C) The American Society for Clinical Investigation, Inc.

0021-9738/94/04/1493/09 \$2.00

Volume 93, April 1994, 1493-1501 mains that make up the large, active proteolytic subunits of factors V and VIII of the coagulation cascade (2). Ceruloplasmin is an acute phase protein with a response of intermediate magnitude compared with other acute phase proteins; the plasma concentration is increased two- to threefold during inflammation, pregnancy, and after traumatic injury, including surgery (see references 3 and 4 for review).

The physiological function of ceruloplasmin has been a subject of considerable investigation, speculation, and contradiction. Multiple biochemical activities of ceruloplasmin have been described, including copper transport, oxidation of various amines, oxidation of $\mathrm{Fe}^{2+}$ to $\mathrm{Fe}^{3+}$ for subsequent uptake by transferrin and ferritin, and antioxidant activity against lipid peroxidation (see references 4 and 5 for evidence for and against these functions). Reported cellular actions of ceruloplasmin include stimulation of cell proliferation (6) and angiogenesis (7). Ceruloplasmin's antioxidant property has been consistently observed by many laboratories (8-13), and is thought by some to be responsible for a large portion of the antioxidant capacity of serum (8). The antioxidant action has been proposed as a crucial function of ceruloplasmin during inflammatory and acute phase responses(14). Multiple mechanisms have been proposed to explain ceruloplasmin antioxidant activity, including scavenging of superoxide and other reactive oxygen species $(10)$, and inhibiting the Fenton reaction by conversion of $\mathrm{Fe}^{2+}$ to $\mathrm{Fe}^{3+}$ (ceruloplasmin is also called "ferroxidase") $(12,15)$. The latter mechanism is supported by a considerable body of evidence, but the ability of ceruloplasmin to block $\mathrm{Cu}^{2+}$-mediated lipid oxidation suggests that alternate antioxidant mechanisms must also pertain (16). There is evidence that ceruloplasmin as an antioxidant blocks protein (17) and DNA damage (18), and that it affords protection against free radical-initiated cell injury and lysis (19).

Ceruloplasmin has been shown to inhibit the oxidation of tissue homogenates (8), tissue extracts of lipids (18), microsomal membranes $(11,12,20)$, and vesicles of purified polyunsaturated fatty acids (9) and phospholipids (10), but its role in the oxidation of plasma lipoproteins has received little attention. This activity of physiological antioxidants has become a subject of intense interest since there is convincing evidence that lipoproteins are modified by oxidation in vivo. Lipoprotein particles resembling oxidized forms have been observed in normal human plasma $(21,22)$, in plasma of diabetic subjects (23), and in the serum of patients with cardiovascular diseases (24). The data demonstrating the presence of oxidized LDL within arterial lesions are particularly strong (25). Evidence that lipid oxidation has a causative role in lesion formation is largely circumstantial and based on in vitro studies. However, recent data show that several antioxidants reduce atherosclerosis progression in various animal models (26-29), and some are associated with reduced risk of cardiovascular disease in humans $(30,31)$.

The cellular and metabolic pathways by which lipids found in atherosclerotic lesions are oxidized are not yet known, but are likely to involve either pathological increases in oxidant 
activity, possibly via cell-mediated free radical processes, or deficiencies in the antioxidant activity of host defense systems. We therefore examined the ability of ceruloplasmin, as a putative plasma antioxidant, to protect LDL against modification by copper ion-mediated free radical oxidation. Our results indicate that ceruloplasmin can exhibit a potent oxidant, rather than antioxidant, activity that depends on specific structural properties of the molecule.

\section{Methods}

Materials. LDL and ceruloplasmin were isolated from fresh human plasma ( $<48 \mathrm{~h}$ ) obtained from the American Red Cross. Rabbit polyclonal antibodies against human ceruloplasmin and human $\alpha_{1}$-antitrypsin were obtained from Accurate Chemical Co. (Westbury, NY). Chromatographic media were purchased from Pharmacia LKB Biotechnology AB (Uppsala, Sweden ), and Chelex-100 was from Bio-Rad Laboratories (Richmond, CA). Other reagents were from Sigma Chemical Co. (St. Louis, MO) unless otherwise noted.

Preparation of human ceruloplasmin. Ceruloplasmin was purified from human plasma by a modification (31a) of the method of Noyer et al. (32). In brief, QAE-Sephadex A50 batch chromatography, ammonium sulfate precipitation, hydroxyapatite chromatography, Sephadex G50 chromatography, ultrafiltration, and Mono Q fast protein liquid chromatography steps were applied sequentially. Hydroxyapatite chromatography yielded two peaks of ceruloplasmin differing only in carbohydrate content (33). The major fraction, referred to as ceruloplasmin I ( or for brevity, just ceruloplasmin), has three N-linked oligosaccharides, while the lesser fraction, ceruloplasmin II, has only two oligosaccharides (4). Each of these fractions was separately subjected to the subsequent purification steps. The procedure was monitored by ceruloplasmin oxidase activity measured essentially as described by Sunderman and Nomoto (34) with $p$-phenylenediamine as substrate. The term "oxidase activity" is used here to refer to the ability of ceruloplasmin to oxidize $p$-phenylenediamine, while "oxidant activity" refers to the oxidation of LDL by ceruloplasmin (see below). Ceruloplasmin protein was determined by absorbance $\left(\mathrm{OD}_{1 \mathrm{~cm}, 610 \mathrm{~nm}}^{1 \%}=0.66\right)$ and total protein with bicinchoninic acid (Bio-Rad Laboratories) using bovine serum albumin as standard. The purification procedure yielded ceruloplasmin preparations that were essentially pure as determined by ceruloplasmin oxidase specific activity (34), by an absorbance ratio $(610 / 280 \mathrm{~nm})>0.045 \cdot(4,35)$, and by homogeneity according to SDSPAGE and silver staining. Purified ceruloplasmin was primarily the intact 132-kD monomer, but also contained a small amount $(<10 \%$ by silver stain of SDS-PAGE) of the 115- and 19-kD proteolytic fragments of ceruloplasmin also present in serum (36). The $115-\mathrm{kD}$ fragment has been observed in most preparations of ceruloplasmin (unless it is further degraded to 50 - and $67-\mathrm{kD}$ fragments) $(37,38)$. Ceruloplasmin prepared by this procedure was completely stable for prolonged periods $\left(>1 \mathrm{mo}\right.$ at $37^{\circ} \mathrm{C}$ ) due to the removal of an endogenous metalloproteinase that specifically cleaved intact, $132-\mathrm{kD}$ ceruloplasmin into 115 - and $19-\mathrm{kD}$ fragments. The material was stored at $-70^{\circ} \mathrm{C}$. Human ceruloplasmin was also obtained from Sigma Chemical Co. and Serva Biochemicals (Westbury, NY). Ceruloplasmin copper content was determined by flame atomic absorption spectrophotometry (3030B; Perkin-Elmer Corp., Norwalk, CT).

Electrophoresis. Samples were dissolved in Laemmli buffer (39) containing $10 \mathrm{mM}$ dithiothreitol for SDS-PAGE, or in Laemmli buffer without SDS for nondenaturing PAGE, and subjected to electrophoresis on $4-12 \%$ polyacrylamide gels (Novex, Encinitas, CA). Protein bands were detected by silver staining (Integrated Separation Systems, Natick, MA) and molecular weights derived by comparison to Mark 12 (Novex) or Rainbow protein standards (Amersham Corp., Arlington Heights, IL). Flat-bed agarose electrophoresis was done using a Trisacetate buffer system in the absence of EDTA.

Lipoprotein methods. Human LDL was prepared from freshly drawn, citrated normolipemic plasma to which EDTA was added be- fore ultracentrifugation. LDL (density $=1.019-1.063 \mathrm{~g} / \mathrm{ml}$ ) was isolated by sequential ultracentrifugation as described previously (40). Immediately before use, LDL was extensively dialyzed at $4^{\circ} \mathrm{C}$ against saline. LDL ( $1 \mathrm{mg} / \mathrm{ml}$ cholesterol, final concentration) was oxidized by incubation with $\mathrm{CuSO}_{4}(0.7-1.0 \mu \mathrm{M})$ and other test materials in $0.05 \mathrm{ml}$ PBS for $20-24 \mathrm{~h}$ at $37^{\circ} \mathrm{C}$. Lipcprotein oxidation was measured as formation of thiobarbituric acid-reacting substances (TBARS) ${ }^{1}$ by a modification (41) of the method of Schuh et al. (42). Duplicate lipoprotein samples were compared with a standard curve prepared with malondialdehyde (MDA), and TBARS, detected by fluorescence at $515 \mathrm{~nm}$ excitation $/ 553 \mathrm{~nm}$ emission, were expressed as nanomoles of MDA equivalents per milligram LDL cholesterol. In some experiments lipoprotein oxidation was continuously monitored as the formation of conjugated dienes by absorbance at $234 \mathrm{~nm}$ (43). The total lipid peroxide content of modified lipoproteins was measured as described by El-Saadani et al. (44). Relative electrophoretic mobility of modified LDL was determined by electrophoresis on $1 \%$ agarose gels (Ciba Corning, Palo Alto, CA) as described by Morel et al. (40), except that the electrophoresis was extended to $45 \mathrm{~min}$ to improve separation.

\section{Results}

Oxidant activity of ceruloplasmin. To investigate the hypothesis that human ceruloplasmin protects lipoproteins against oxidative modification, we examined its effect on copper ion-induced oxidation of human plasma $\mathrm{LDL}$. $\mathrm{CuSO}_{4}$ alone increased LDL TBARS by $\sim 15$-fold to $16 \mathrm{nmol}$ MDA equivalents/mg cholesterol, a stimulation consistent with previous reports $(45,46)$. Surprisingly, the addition of purified, intact human ceruloplasmin did not suppress the oxidation of LDL by $\mathrm{CuSO}_{4}$, but rather augmented it in a dose-dependent manner to as much as $25 \mathrm{nmol} \mathrm{MDA} / \mathrm{mg}$ cholesterol (Fig. 1). To test if the oxidant activity of ceruloplasmin required exogenous copper ions, the effect of ceruloplasmin by itself was tested. Incubation of LDL with ceruloplasmin for $24 \mathrm{~h}$ increased oxidation levels by $\sim 40$-fold to $39 \mathrm{nmol} \mathrm{MDA} / \mathrm{mg}$ cholesterol at the normal (nonevoked) physiological plasma concentration of $300 \mu \mathrm{g} / \mathrm{ml}$ (Fig. 2). Potent oxidant activity was observed in all 4 preparations of ceruloplasmin (isolated from different pools of plasma) that were tested, and using at least 10 separate preparations of LDL. Ceruloplasmin oxidant activity was comparable to that of $\mathrm{CuSO}_{4}$ (when expressed as moles of ceruloplasmin protein and moles of $\mathrm{CuSO}_{4}$ ), with the activity of different ceruloplasmin preparations ranging from about half as potent to twice as potent as the soluble salt (not shown ). If ceruloplasmin copper is involved in oxidant activity (see below), then it is likely that not all copper atoms participate in the reaction or that the involved atoms are less effective than free copper. As a control to show whether ceruloplasmin altered the measurement of TBARS, ceruloplasmin was added to LDL immediately before the assay and was found to have no influence on the TBARS measured.

To verify that LDL was indeed oxidized by ceruloplasmin, other physical and chemical parameters of lipid and lipoprotein oxidation were measured. Since ceruloplasmin contains between six and seven atoms of copper per molecule $(35,47)$, we speculated that the chemical characteristics of LDL oxidized by ceruloplasmin would be similar to those of copper-oxidized LDL. Concentrations of ceruloplasmin $(100 \mu \mathrm{g} / \mathrm{ml}$,

1. Abbreviations used in this paper: MDA, malondialdehyde; TBARS, thiobarbituric acid-reacting substances. 


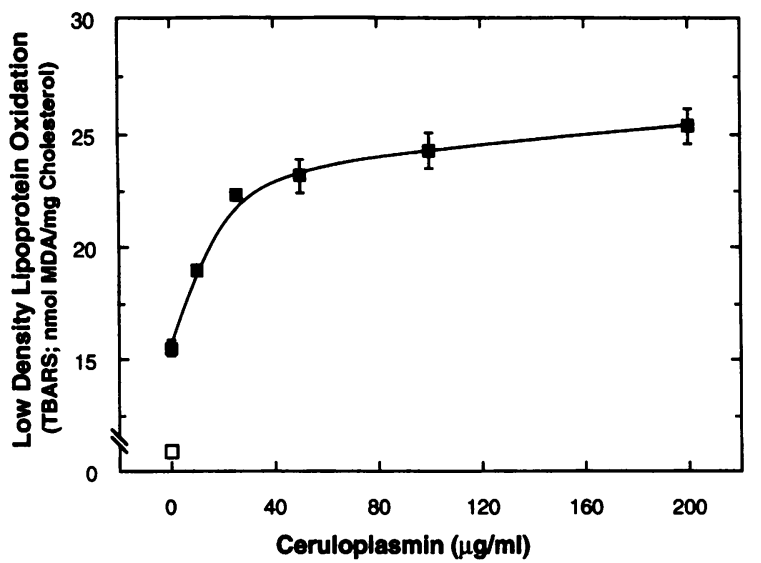

Figure 1. Oxidant activity of human ceruloplasmin. LDL $(1 \mathrm{mg} / \mathrm{ml}$ cholesterol, final concentration) was oxidized by incubation with $\mathrm{CuSO}_{4}(0.7 \mu \mathrm{M})$ in the presence of intact, purified human ceruloplasmin I $(a)$ for $20 \mathrm{~h}$ at $37^{\circ} \mathrm{C}$ in a final volume of $0.05 \mathrm{ml}$. Oxidation levels of treated and untreated LDL $(\square)$ were determined as TBARS and expressed as nanomoles MDA equivalents per milligram LDL cholesterol.

equivalent to $0.75 \mu \mathrm{M})$ and $\mathrm{CuSO}_{4}(0.7 \mu \mathrm{M})$ were chosen to give similar values of TBARS after $24 \mathrm{~h}$ of incubation at $37^{\circ} \mathrm{C}$. The initial rate and extent of formation of TBARS (Fig. $3 \mathrm{~A}$ ), total lipid peroxides (Fig. $3 B$ ), and conjugated dienes (Fig. 3 $C$ ) were nearly identical for both oxidants. As further evidence of lipoprotein oxidation, incubation of LDL with the same concentrations of ceruloplasmin or $\mathrm{CuSO}_{4}$ for $20 \mathrm{~h}$ at $37^{\circ} \mathrm{C}$ increased its relative electrophoretic mobility by 63 and $56 \%$, respectively (not shown). The similar responses confirm the oxidant nature of ceruloplasmin and suggest similar mechanisms of action for ceruloplasmin and free copper ion.

The oxidant activities of the differentially glycosylated isoforms of ceruloplasmin were evaluated. Ceruloplasmin I and II exhibited nearly identical oxidant potencies with respect to modification of LDL (Fig. $4 A$ ). Both isoforms gave half-maximal oxidation at a concentration near $25 \mu \mathrm{g} / \mathrm{ml}$ and maximal oxidation at $\sim 200 \mu \mathrm{g} / \mathrm{ml}$. Although ceruloplasmin prepared

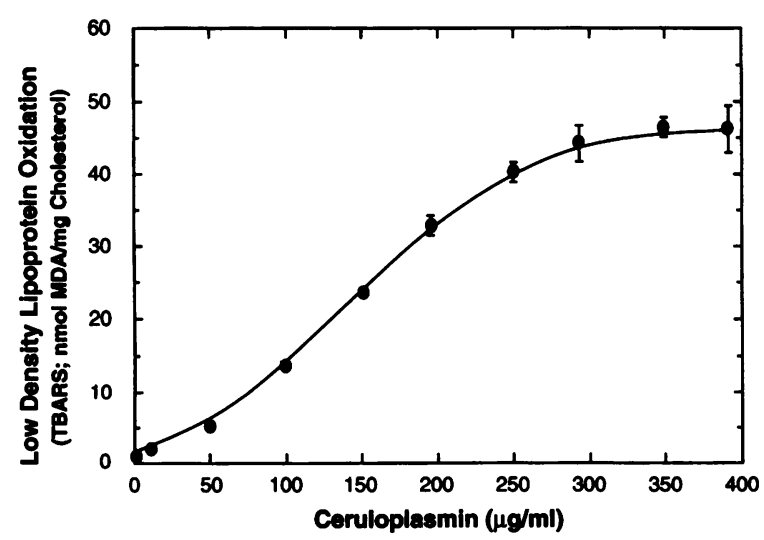

Figure 2. Concentration dependence of LDL oxidation by ceruloplasmin. LDL ( $1 \mathrm{mg} / \mathrm{ml}$ cholesterol) was oxidized by incubation for $24 \mathrm{~h}$ at $37^{\circ} \mathrm{C}$ with ceruloplasmin I (•). Lipoprotein oxidation was determined as TBARS and expressed as nanomoles MDA equivalents per milligram LDL cholesterol.

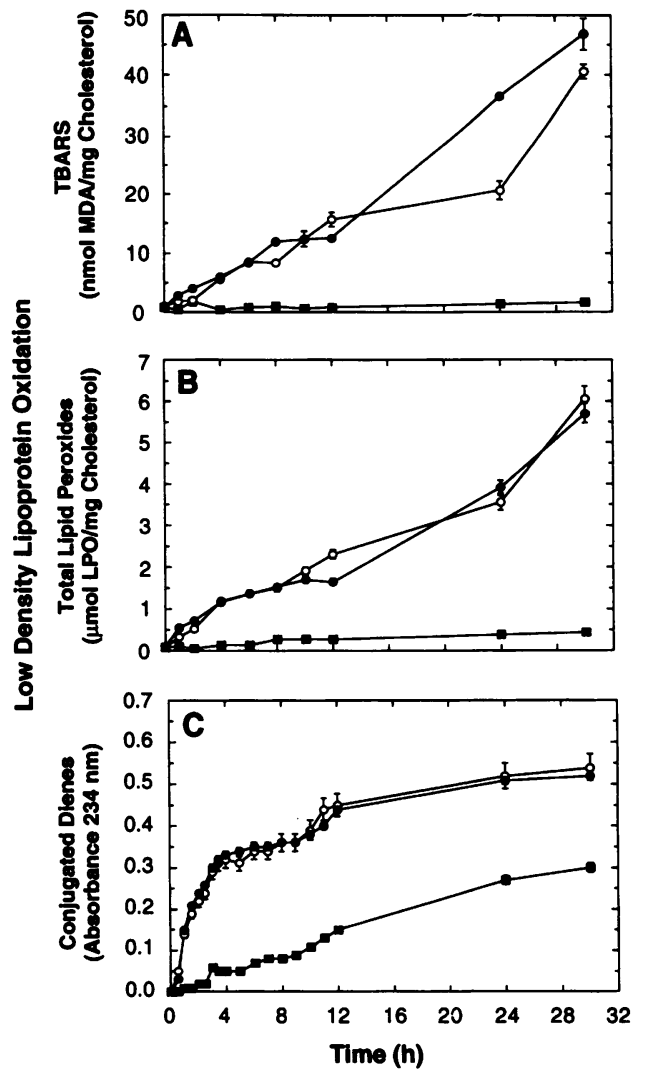

Figure 3. Time course of oxidation of $\mathrm{LDL}$ by $\mathrm{CuSO}_{4}$ and ceruloplasmin. $\mathrm{LDL}$ ( $1 \mathrm{mg} / \mathrm{ml}$ cholesterol) was oxidized in the presence of $100 \mu \mathrm{g} / \mathrm{ml}$ ceruloplasmin I (•), $0.7 \mu \mathrm{M} \mathrm{CuSO}_{4}(0)$, or buffer ( $\bullet$ ) for $30 \mathrm{~h}$ at $37^{\circ} \mathrm{C}$ in a final volume of $0.05 \mathrm{ml}$. Aliquots were taken at indicated times and lipid oxidation determined $(A)$ as TBARS and expressed as nanomoles MDA equivalents per milligram LDL cholesterol, $(B)$ as total lipid peroxides (LPO) and expressed as micromoles per milligram cholesterol, or $(C)$ as conjugated dienes and expressed as absorbance at $234 \mathrm{~nm}$ (after a 1:10 dilution with PBS).

in our laboratory is highly homogeneous, its oxidant activity could have been due to a minor contaminant. To examine this possibility two approaches were taken. First, ceruloplasmin oxidant activity was tested after further purification by electrophoresis on agarose gels, followed by elution of the ceruloplasmin band. Fig. $4 B$ shows that after elution, both glycosylated isoforms had highly potent activities that were only slightly diminished compared with the original material. In a second approach, ceruloplasmin was removed by immunoadsorption using a specific polyclonal anticeruloplasmin antibody. The antibody was shown to be mono-specific since only a single protein (which comigrated with authentic human ceruloplasmin) was recognized in human serum by Western blot analysis (not shown). Protein A-Sepharose 4B beads were preincubated with rabbit antibodies raised against either human ceruloplasmin or $\alpha_{1}$-antitrypsin, and the antibody-bead complexes collected after low-speed centrifugation. Purified ceruloplas$\min \mathrm{I}(40 \mu \mathrm{g})$ was incubated with the beads for $12 \mathrm{~h}$ at $4^{\circ} \mathrm{C}$, and the low-speed supernatants were recovered and tested for oxidant activity. Measurement of ceruloplasmin oxidase activity in the precipitate confirmed that immunoadsorption with anticeruloplasmin, but not anti- $\alpha_{1}$-antitrypsin, removed at least $90 \%$ of the ceruloplasmin. The anticeruloplasmin antibody removed $\sim 85 \%$ of the oxidant activity while only $15 \%$ was removed by an irrelevant antibody (Fig. 5). These results indi- 


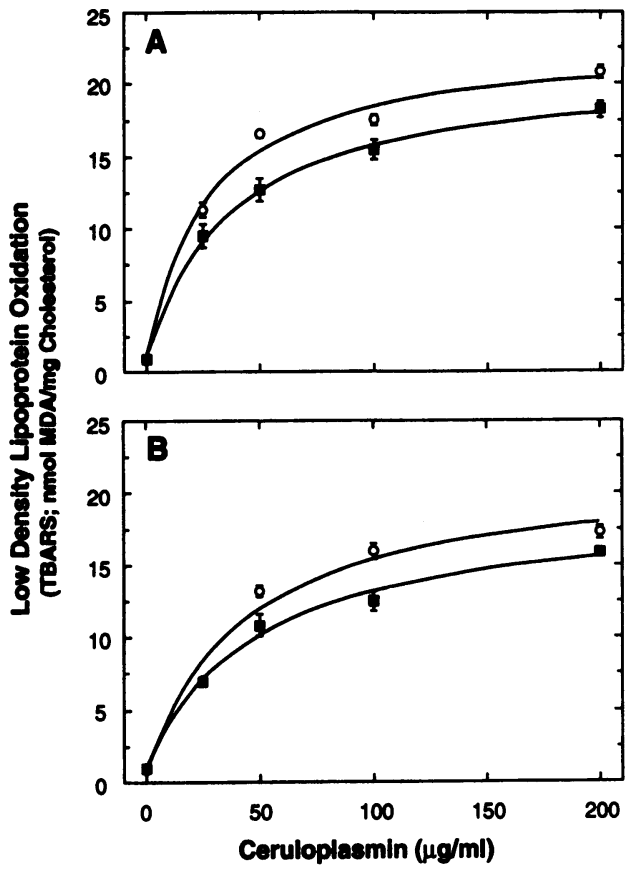

Figure 4. Oxidant activity of two isoforms of human ceruloplasmin differing in carbohydrate content. $(A) \mathrm{LDL}(1 \mathrm{mg} / \mathrm{ml}$ cholesterol) was oxidized by incubation with the purified, undegraded human isoforms, ceruloplasmin I (O) and II ( $)$, for $20 \mathrm{~h}$ at $37^{\circ} \mathrm{C}$ in a final volume of $0.05 \mathrm{ml}$. (B) Both isoforms $(500 \mu \mathrm{g}$ ) were further resolved on $1 \%$ agarose gels in Tris-acetate buffer in the absence of EDTA. The ceruloplasmin bands (visible without staining) were excised, cut into small pieces, and eluted by incubation with PBS for $10 \mathrm{~h}$ at $25^{\circ} \mathrm{C}$. Agarose pieces were removed by centrifugation ( $15,000 \mathrm{~g}$ for $10 \mathrm{~min}$ ) and ceruloplasmin was dialyzed extensively against PBS. Eluted ceruloplasmin was incubated with LDL as described in $A$. Lipoprotein oxidation was determined as TBARS and expressed as nanomoles MDA equivalents per milligram LDL cholesterol.

cate that it is ceruloplasmin rather than a minor contaminant that is responsible for oxidant activity.

Regulation of ceruloplasmin oxidant activity. Since the oxidant action of ceruloplasmin was not consistent with previous reports of antioxidant activity, we tested the effect of ceruloplasmin from commercial suppliers used in most previous reports on oxidation of lipids. Commercial ceruloplasmin had essentially no capacity to oxidize LDL in the absence of exogenous copper ion; the maximum oxidation level was $1-3 \mathrm{nmol}$ MDA equivalents/mg cholesterol, compared with 20-40 for intact, purified ceruloplasmin (Fig. 6). When added in the presence of $\mathrm{CuSO}_{4}$, commercial ceruloplasmin was found to be an antioxidant, a finding consistent with previous reports. This result contrasted with that for intact, $132-\mathrm{kD}$ ceruloplasmin, which augmented copper ion-mediated LDL oxidation (Fig. 1). According to SDS-PAGE, purified ceruloplasmin I was highly homogeneous and present primarily as an intact 132-kD protein with only a small amount $(<10 \%)$ of the $115-\mathrm{kD}$ degradation product. This proportion of intact protein to the 115kD fragment is similar to that observed by Western blot analysis of whole plasma (36, and data not shown). Electrophoresis on a nondenaturing gel confirmed the purity of ceruloplasmin I (Fig. 6, inset); the 115- and 19-kD degradation products remained complexed under these conditions and cochromatographed with the intact protein. The $132-\mathrm{kD}$ protein was entirely missing from the commercial preparation and was re-

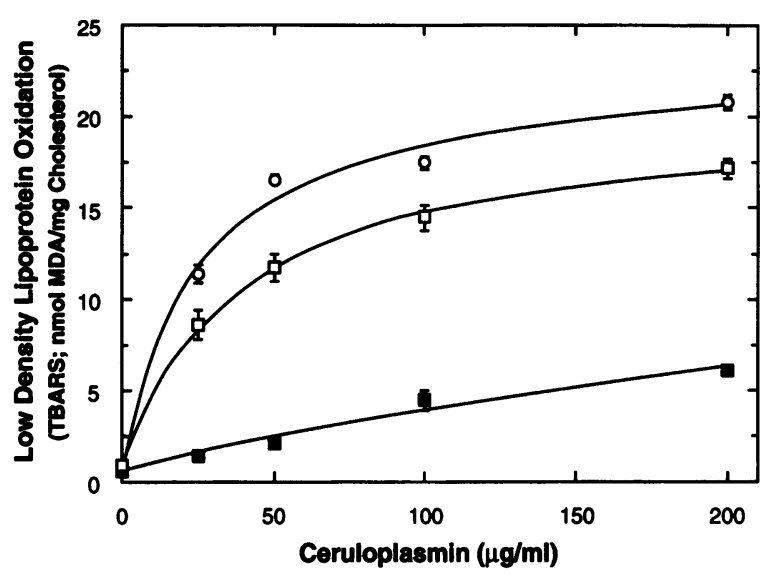

Figure 5. Removal of oxidant activity of ceruloplasmin by immunoadsorption with anticeruloplasmin. Protein A-Sepharose 4B was pretreated with $0.2 \%$ bovine serum albumin to reduce nonspecific binding. After extensive washing with PBS, $0.2 \mathrm{ml}$ of beads was incubated overnight at $4^{\circ} \mathrm{C}$ with $0.2 \mathrm{ml}$ of rabbit antibody against human ceruloplasmin or $\alpha_{1}$-antitrypsin as a control for nonspecific binding. The antibody/protein A-Sepharose complexes were precipitated, washed with PBS, and incubated with $40 \mu \mathrm{g}$ ceruloplasmin I at $4^{\circ} \mathrm{C}$ overnight. $\mathrm{LDL}$ ( $1 \mathrm{mg} / \mathrm{ml}$ cholesterol) was incubated for $20 \mathrm{~h}$ at $37^{\circ} \mathrm{C}$ (final volume of $0.05 \mathrm{ml}$ ) with ceruloplasmin I (O), the supernatant adsorbed with anticeruloplasmin antibody $(\bullet)$, or the supernatant similarly treated with anti- $\alpha_{1}$-antitrypsin antibody (ㅁ). Lipoprotein oxidation was determined as TBARS and expressed as nanomoles MDA-equivalents per milligram LDL cholesterol.

placed by lower molecular mass fragments (Fig. 6, inset) and, possibly, nonceruloplasmin contaminants. Similar antioxidant capacities were found using ceruloplasmin from several commercial sources, all of which were highly degraded but retained normal levels of ceruloplasmin oxidase-specific activity that were comparable to that of purified ceruloplasmin I (not shown).

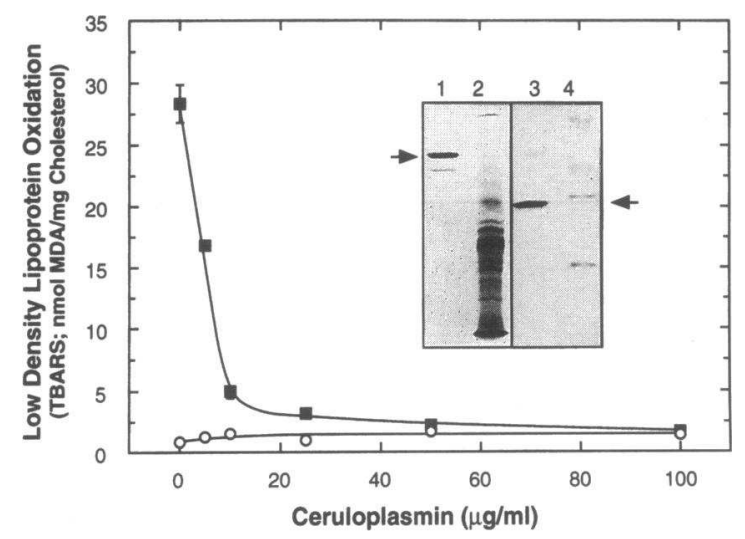

Figure 6. Effect of commercially obtained ceruloplasmin on LDL oxidation. $\mathrm{LDL}$ ( $1 \mathrm{mg} / \mathrm{ml}$ cholesterol ) was oxidized by incubation for $20 \mathrm{~h}$ at $37^{\circ} \mathrm{C}$ with commercial ceruloplasmin in the absence (o) or presence ( $\left(\right.$ ) of $0.7 \mu \mathrm{M} \mathrm{CuSO}_{4}$. Lipoprotein oxidation was determined as TBARS and expressed as nanomoles MDA equivalents per milligram LDL cholesterol. The insert shows $100 \mathrm{ng}$ of purified human ceruloplasmin I (lane 1) and commercial human ceruloplasmin (lane 2) resolved by SDS-PAGE and detected by silver stain. The same preparations were also resolved by nondenaturing PAGE (lanes 3 and 4, respectively). The arrows indicate the $132-\mathrm{kD}$ ceruloplasmin. 
To begin to understand the molecular mechanisms involved, we examined the role of ceruloplasmin structure in oxidant activity. We first examined whether the difference in structural integrity of the ceruloplasmin preparations could account for the observed difference in oxidant activity. Proteolytically modified ceruloplasmin was prepared by incubating highly purified, intact ceruloplasmin I with the plasma metalloproteinase that was isolated during the ceruloplasmin preparation and partially purified (31a). After incubation for $72 \mathrm{~h}$ at $37^{\circ} \mathrm{C}$, the $132-\mathrm{kD}$ ceruloplasmin molecule was completely converted to the 115-kD fragment (Fig. $7 \mathrm{~A}$, inset). Both degraded and undegraded forms of ceruloplasmin were incubated with LDL for $24 \mathrm{~h}$ and the level of oxidation measured as TBARS. Proteolytically modified ceruloplasmin lost about three-fourths of the oxidant activity of the intact molecule (Fig.

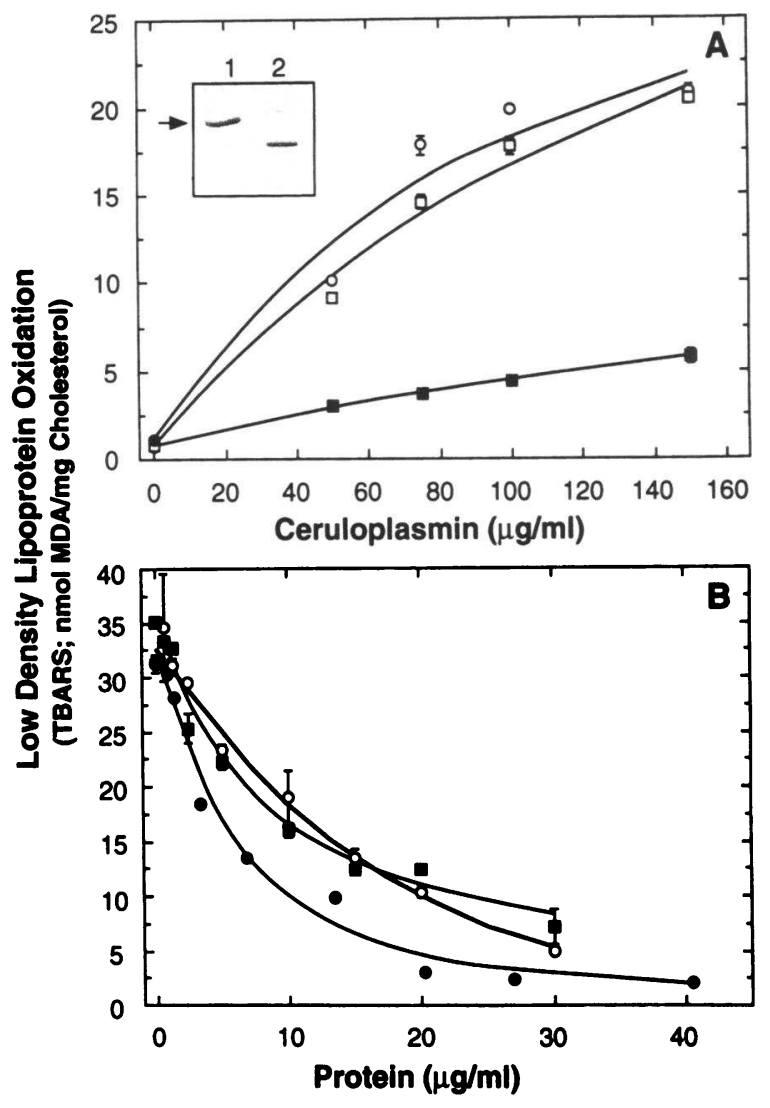

Figure 7. Effect of proteolytic modification on ceruloplasmin oxidant and antioxidant activity. $(A)$ Ceruloplasmin I ( $200 \mu \mathrm{g})$ was preincubated with (designated "proteolytically modified ceruloplasmin") or without (designated "intact ceruloplasmin"), a partially purified plasma metalloproteinase preparation $(\leq 10 \mathrm{ng})$ for $72 \mathrm{~h}$ at $37^{\circ} \mathrm{C}$ in $200 \mu \mathrm{l}$ of $25 \mathrm{mM}$ Tris- $\mathrm{HCl}, 10 \mathrm{mM} \mathrm{CaCl}_{2}, \mathrm{pH}$ 6.6. The 132-kD ceruloplasmin (inset, lane 1 ) was completely modified to the $115-\mathrm{kD}$ form (inset, lane 2 ) as shown by silver-stained SDS-PAGE ( $100 \mathrm{ng}$ protein/lane). The arrow indicates $132-\mathrm{kD}$ ceruloplasmin. LDL $(1 \mathrm{mg} /$ $\mathrm{ml}$ cholesterol) was incubated for $20 \mathrm{~h}$ at $37^{\circ} \mathrm{C}$ with intact ceruloplasmin $(0)$, proteolytically modified ceruloplasmin $(\square)$, or intact ceruloplasmin with the same amount of metalloproteinase added just before the incubation with LDL ( $\square$ ). (B) LDL $(1 \mathrm{mg} / \mathrm{ml}$ cholesterol) was incubated for $20 \mathrm{~h}$ at $37^{\circ} \mathrm{C}$ with $0.8 \mu \mathrm{M} \mathrm{CuSO}_{4}$ in the presence of commercial ceruloplasmin $(\bullet)$, proteolytically modified ceruloplasmin I ( $₫)$, or bovine serum albumin (O). Lipoprotein oxidation was determined as TBARS and expressed as nanomoles MDA equivalents per milligram LDL cholesterol.
$7 \mathrm{~A}$ ). Addition of the protease just before the incubation with LDL did not substantially reduce the oxidant activity of ceruloplasmin, showing that the small amount of protease present did not exhibit nonspecific antioxidant activity (see below). Structural differences between native and proteolytically modified ceruloplasmin are likely to be subtle since the proteins cochromatograph on nondenaturing gels (indicating a stable complex of the fragments under these conditions), they contain equal amounts of copper by atomic absorption spectroscopy ( 6.6 and 6.7 atoms per ceruloplasmin for native and proteolytically modified protein, respectively), and the degraded protein retains $90 \%$ of the oxidase activity of intact ceruloplasmin (not shown). In addition to the loss in oxidant activity, proteolytic modification of ceruloplasmin induces antioxidant activity when incubated with $\mathrm{LDL}$ in the presence of $\mathrm{CuSO}_{4}$ (Fig. $7 \mathrm{~B}$ ). The antioxidant activity of proteolytically modified ceruloplasmin was similar to that of bovine serum albumin and only moderately less than commercial ceruloplasmin. These findings are consistent with those of Gutteridge (16), who has shown that, in a cupric ion system, the antioxidant activity of (degraded) ceruloplasmin is not unique, but rather is a nonspecific property of most proteins. Kalant and McCormick (48) have similarly shown that albumin and other serum proteins suppress metal ion-mediated oxidation of LDL.

We compared the ability of various proteins to inhibit ceruloplasmin-mediated as well as $\mathrm{CuSO}_{4}$-mediated LDL oxidation. All proteins and peptides tested suppressed both $\mathrm{CuSO}_{4}$ dependent (Fig. $8 \mathrm{~A}$ ) and ceruloplasmin-dependent (Fig. $8 \mathrm{~B}$ ) oxidation in a concentration-dependent fashion, and with a rank order of potency of lactalbumin hydrolysate $>$ albumin

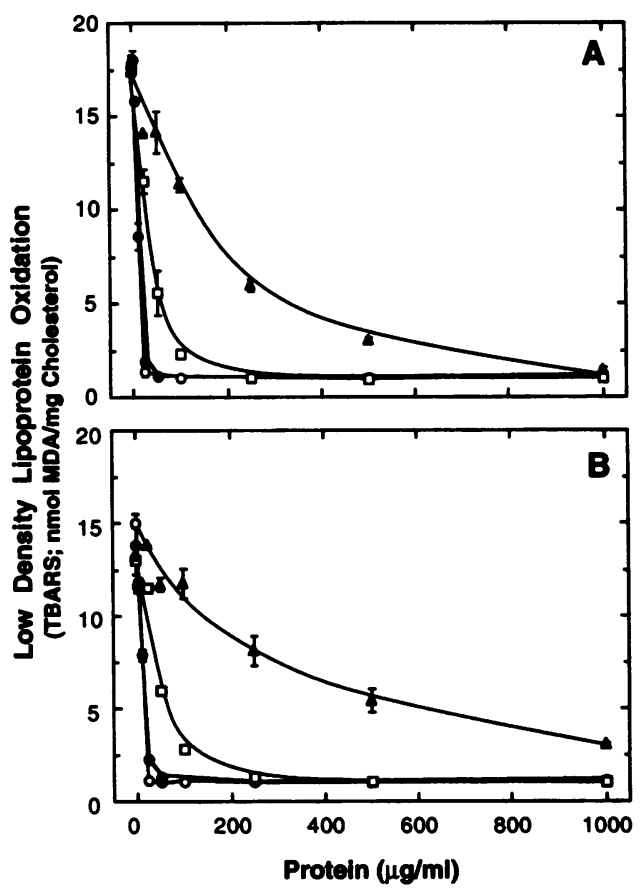

Figure 8. Inhibition of copper- and ceruloplasmin-mediated LDL oxidation by proteins. $(A) \mathrm{LDL}(1 \mathrm{mg} / \mathrm{ml}$ cholesterol $)$ was oxidized by incubation for $20 \mathrm{~h}$ at $37^{\circ} \mathrm{C}$ with $0.7 \mu \mathrm{M} \mathrm{CuSO}_{4}$ in the presence of lactalbumin hydrolysate $(0)$, bovine serum albumin $(\bullet)$, gelatin ( $\square$ ), or type I collagen ( $\triangle$ ). (B) Same as in $A$, but with $50 \mu \mathrm{g} / \mathrm{ml}$ ceruloplasmin I instead of $\mathrm{CuSO}_{4}$. Lipoprotein oxidation was determined as TBARS and expressed as nanomoles MDA equivalents per milligram LDL cholesterol. 
$\approx$ proteolytically modified ceruloplasmin $>$ gelatin $>$ type I collagen. All proteins inhibited LDL oxidation by $\mathrm{CuSO}_{4}$ and by ceruloplasmin with similar potencies, suggesting that the mechanisms of oxidant activity by both agents may be related. The results show that protein contaminants can interfere with ceruloplasmin oxidant activity and, in conjunction with degradation, may account for differences in oxidant activity of ceruloplasmin preparations. They also show that in cupric ion-mediated or in intact ceruloplasmin-mediated oxidation, the antioxidant activity of degraded or commercial sources of ceruloplasmin is a nonspecific effect in common with many proteins.

Bound ceruloplasmin copper is responsible for oxidant activity. The parallel time courses of oxidation of LDL by ceruloplasmin and by $\mathrm{CuSO}_{4}$ described above (and parallel inhibition by proteins) suggest that copper may be responsible for ceruloplasmin oxidant activity. Since the purification of ceruloplasmin involved multiple column elutions (some under conditions of high ionic strength) and multiple filtration steps, we did not believe it likely that significant amounts of free copper could be copurifying with the protein. To test the possibility directly, the oxidant activity of ceruloplasmin was examined after thorough washing by ultrafiltration using 10-kD Microcon filters (Amicon Corp., Danvers, MA). Approximately $90 \%$ of the oxidant activity was retained by the filter and $<10 \%$ passed through, confirming the association of the oxidant copper atoms with ceruloplasmin. To further test the hypothesis that ceruloplasmin copper was responsible for LDL oxidation, we examined the ability of a chelating agent, Chelex-100, to inactivate ceruloplasmin. Ceruloplasmin was incubated with Chelex-100 beads for $4 \mathrm{~h}$ at room temperature and the supernatant assayed for its ability to oxidize LDL. This treatment decreased ceruloplasmin copper content from $\sim 6.6$ to 5.5 atoms per molecule of protein, a result consistent with the removal of 1 of 7 copper atoms as reported previously (47). Incubation of ceruloplasmin with Chelex- 100 completely suppressed the oxidant activity of the protein (Fig. 9) without significantly altering oxidase activity (not shown). As was the case with protease treatment, suppression of ceruloplasmin oxidant activity by treatment with Chelex-100 was accompanied by the appearance of antioxidant activity as determined by inhibition of LDL oxidation in the presence of $\mathrm{CuSO}_{4}$ (not shown). Restoration of copper by incubation with $\mathrm{CuSO}_{4}$ ( followed by ultrafiltration) almost completely restored oxidant activity to Chelex-treated ceruloplasmin. This demonstrates that the inactivation by Chelex-100 was not due to irreversible changes in the oxidant capacity of the protein and confirms the critical role of copper in ceruloplasmin oxidant activity.

\section{Discussion}

These experiments demonstrate that purified, undegraded human ceruloplasmin has potent oxidant activity towards LDL. We have several lines of evidence that this activity is due to ceruloplasmin itself and not to a minor contaminant: $(a)$ the ceruloplasmin used in these experiments is homogeneous by silver staining of SDS-PAGE, by ceruloplasmin oxidase specific activity, and by an absorbance ratio $(610 / 280 \mathrm{~nm})$ of at least $0.045 ;(b)$ both glycosylated isoforms of ceruloplasmin have equal oxidant capability; $(c)$ ceruloplasmin eluted from nondenaturing agarose gels is highly active; $(d)$ two treatments known to specifically alter ceruloplasmin structure, i.e., incubation with a ceruloplasmin-degrading protease and with Che-

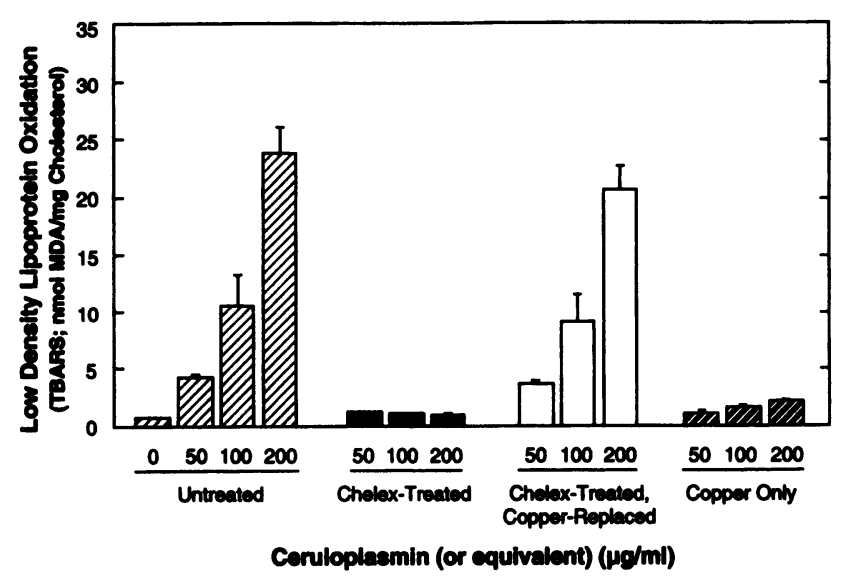

Figure 9. Effect of copper depletion on ceruloplasmin oxidant activity. Purified ceruloplasmin I ( $200 \mu \mathrm{g})$ was incubated with Chelex-100 ( $150 \mu$ l of beads washed with metal ion-free PBS) for $4 \mathrm{~h}$ at $23^{\circ} \mathrm{C}$. An aliquot $\left(100 \mu \mathrm{g}\right.$ ) of the supernatant was incubated with excess $\mathrm{CuSO}_{4}$ $(10 \mu \mathrm{M})$ for $2 \mathrm{~h}$ at room temperature followed by washing by repeated ultrafiltration (6-10 times) to remove unbound copper. LDL ( $1 \mathrm{mg} /$ $\mathrm{ml}$ cholesterol) was oxidized by incubated for $20 \mathrm{~h}$ at $37^{\circ} \mathrm{C}$ with untreated ceruloplasmin (light hatched bars), with Chelex-treated ceruloplasmin (black bars), with Chelex-treated ceruloplasmin that underwent $\mathrm{CuSO}_{4}$ replacement (open bars), or, as a control to make sure that free $\mathrm{CuSO}_{4}$ was removed by the wash procedure, with an ultra-filtered $\mathrm{CuSO}_{4}$ solution (ceruloplasmin-free) equivalent to that used in the copper replacement treatment (dark hatched bars). Lipoprotein oxidation was determined as TBARS and expressed as nanomoles MDA equivalents per milligram LDL cholesterol.

lex-100, also moderate oxidant activity; and (e) immunoprecipitation by a ceruloplasmin-specific antibody removed essentially all oxidant activity.

The oxidant activity was unanticipated in view of reports from many laboratories that ceruloplasmin is a potent lipid antioxidant (see references 14 and 49 for review). We believe that the most likely source of the different results is the purity and structural integrity of ceruloplasmin itself. The purified ceruloplasmin used in this study is prepared from fresh plasma according to a modified protocol that removes a contaminating metalloproteinase and yields an intact 132-kD monomer with minimal degradation to the $115-\mathrm{kD}$ or smaller fragments (31a). The ceruloplasmin from commercial sources is highly degraded with the $132-\mathrm{kD}$ monomer entirely missing and replaced by smaller fragments. We have shown that specific degradation of ceruloplasmin to the 115 - and $19-\mathrm{kD}$ fragments is accompanied by the disappearance of oxidant activity and appearance of antioxidant activity. Similarly, highly degraded commercial ceruloplasmin lacks oxidant activity and is an apparent antioxidant in cupric ion-mediated oxidation of LDL.

While our results suggest a new physiological role for ceruloplasmin that is counter to most current ideas, the seemingly disparate findings are not incompatible. The antioxidant activity of ceruloplasmin can be ascribed to two of its properties. The first is a nonspecific, antioxidant effect that can be observed for almost any protein in, for example, a cupric ion-mediated lipid peroxidation reaction (Fig. 7 and reference 16 ). Second, the oxidase activity of ceruloplasmin, inherent in the intact, purified protein as well as in the degraded protein that dominates commercial preparations, participates in the redox cycling of iron. In lipid peroxidation processes that are iron rather than copper mediated, ceruloplasmin oxidizes ferrous ion to ferric ion and, according to the "mixed valence iron 
model" (50), drives the iron equilibrium from an actively oxidizing mix of both valence states to the inactive ferric state, thus accounting for its antioxidant activity. These two properties could explain the previous reports showing ceruloplasmin to be an antioxidant.

Our results clearly implicate bound copper in ceruloplasmin oxidant activity. The first evidence is the resemblance of ceruloplasmin-oxidized LDL and copper-oxidized LDL with respect to multiple chemical and physical indicators of oxidation. When a concentration of copper is chosen so that the rate of formation of LDL TBARS matches that caused by a given concentration of ceruloplasmin, other measures of LDL oxidation that we have tested also match closely. Furthermore, several proteins block the oxidation of LDL mediated by both free copper and ceruloplasmin, suggesting similar mechanisms. Most importantly, treatment of ceruloplasmin with Chelex100 , which removes a single copper from ceruloplasmin, almost completely suppresses the oxidant activity, which can be subsequently restored by readdition of copper. However, just the presence of the oxidant copper atom(s) is not sufficient for oxidant activity since protease treatment completely suppresses the activity without removing any copper. This result is consistent with a structural modification of the molecule that blocks the accessibility of the oxidant copper site. Interestingly, neither chelation nor proteolysis alter ceruloplasmin oxidase activity, indicating that the active sites and specific copper atoms required for oxidase and oxidant activities may not be the same.

Little is known about the structure of ceruloplasmin in vivo. We and others (36) have shown by Western blot analysis that ceruloplasmin in plasma consists primarily of the intact 132-kD monomer accompanied by a small amount of the 115$\mathrm{kD}$ degradation fragment. We therefore argue that circulating ceruloplasmin is predominantly in the form in which the oxidant rather than antioxidant activity may be expressed. Recent electron paramagnetic resonance studies of plasma have shown that the spectrum of ceruloplasmin in plasma is essentially identical to purified ceruloplasmin (51). In addition to the ceruloplasmin isoforms used in these experiments, other isoforms have been observed in plasma, including an apoceruloplasmin that is completely devoid of copper and a $200-\mathrm{kD}$ molecule, but the amounts and roles of these proteins are uncertain $(36,52,53)$.

The mechanisms causing LDL oxidation in vivo are not known and we can only speculate on the role of ceruloplasmin in this process. There is some evidence for oxidized LDL in plasma $(21,54)$. A process by which ceruloplasmin may oxidize circulating LDL that is then taken up by the artery wall may be envisioned. The accumulation of oxidatively modified LDL in the plasma may be limited by plasma antioxidants and by rapid removal by the liver (55). In an alternate scenario, ceruloplasmin may oxidize LDL within the arterial wall itself. There is as yet no evidence for ceruloplasmin in either normal or lesioned blood vessels. However, ceruloplasmin could accumulate in the vessel wall by at least two pathways: uptake and synthesis. In support of the first mechanism, specific high affinity receptors for ceruloplasmin have been described in liver endothelium (56) and in aortic extracts (57). Alternatively, conditions or procedures that cause vascular injury (surgery or angioplasty), in which ceruloplasmin levels are elevated (58) and endothelial permeability to plasma-borne substances is increased, may result in high interstitial concentrations of both ceruloplasmin and lipoproteins. With respect to the second mechanism, while the liver is believed to be the primary site of synthesis of ceruloplasmin in the adult, activation of alveolar macrophages by inflammatory agents stimulates ceruloplasmin gene expression and protein production (59). A similar activation and response by macrophages in vascular lesions is possible.

Vascular endothelial cells and smooth muscle cells oxidize LDL by mechanisms requiring transition metals $(40,60)$, and activated human monocytes oxidize LDL even in metal ionpoor media $(61,62)$. The role of ceruloplasmin in these processes has not been investigated. Much of the research on the mechanisms of oxidation of LDL by cells has been done with soluble metal ion-dependent systems; however, the existence of free iron and copper ions in vivo is uncertain. Our results invite speculation that the participation of copper in ceruloplasmin-bound form could be an in vivo analogue of metal ion-dependent oxidation of LDL, which could pertain in either cell-free and cell-dependent systems. Other transition metal-containing proteins may also participate in lipoprotein oxidation and, in fact, Balla et al. (63) have shown that the iron-binding protein hemin can oxidize LDL in vitro. Their observations differ from our own in that hemin-mediated oxidation requires a source of peroxides and the addition of exogenous metal ion.

The physiological role of ceruloplasmin has not yet been identified with certainty. Menkes' and Wilson's diseases are inherited human disorders characterized by markedly reduced plasma ceruloplasmin levels (64). These diseases, however, are not particularly informative about the physiological or pathological functions of ceruloplasmin, since the primary defect does not reside within the ceruloplasmin gene, but rather involves defective cellular copper transport, which is likely to affect all copper proteins (65). Our findings recommend a cautious approach when considering the physiological role of ceruloplasmin. Although much previous evidence supports its role as an antioxidant that protects lipids and cells against free radical-induced injury, ceruloplasmin may also have a damaging, oxidant activity. The structure of the molecule in vivo may be of paramount importance in determining its action. Our data indicate that the proportion of ceruloplasmin in the undegraded 132-kD form (compared with degraded) and the presence or chemical coordination of complexed copper atoms are critical parameters in determining the net oxidant activity. The importance of oxidant activity in the physiological role of ceruloplasmin is not known, but it may be central in its primary function, e.g., as a participant in the host defense system through an injurious oxidant action on invasive organisms. This activity is consistent with ceruloplasmin's role in the acute phase response occurring after infection or inflammation and, in fact, a bactericidal activity has been recently reported (66). Inactivation of ceruloplasmin by a metalloproteinase may represent a physiological mechanism to limit the scope of its acute oxidant action. The ability of ceruloplasmin to oxidatively modify LDL may help to explain recent studies showing that serum ceruloplasmin is an independent risk factor in the prediction of myocardial infarction and cardiovascular disease (67-70).

\section{Acknowledgments}

This work was supported by grants HL-40352 and HL-41178 (to P. L. Fox), and HL-47852 and HL-29582 (to G. M. Chisolm) from the National Heart Lung and Blood Institute, National Institutes of 
Health. P. L. Fox is an Established Investigator of the American Heart Association.

\section{References}

1. Ortel, T. L., N. Takahashi, and F. W. Putnam. 1984. Structural model of human ceruloplasmin based on internal triplication, hydrophilic/hydrophobic character, and secondary structure of domains. Proc. Natl. Acad. Sci. USA. 81:4761-4765.

2. Church, W. R., R. L. Jernigan, J. Toole, R. M. Hewick, J. Knopf, G. J. Knutson, M. E. Nesheim, K. G. Mann, and D. N. Fass. 1984. Coagulation factors $\mathrm{V}$ and VIII and ceruloplasmin constitute a family of structurally related proteins. Proc. Natl. Acad. Sci. USA. 81:6934-6937.

3. Gutteridge, J. M., and J. Stocks. 1981. Caeruloplasmin: physiological and pathological perspectives. Crit. Rev. Clin. Lab. Sci. 14:257-329.

4. Rydén, L. 1984. Ceruloplasmin. In Copper Proteins and Copper Enzymes, vol. III. R. Lontie, editor. CRC Press, Inc., Boca Raton, FL. 37-100.

5. Frieden, E. 1986. Perspectives on copper biochemistry. Clin. Physiol. Biochem. 4:11-19.

6. Alcain, F., H. Löw, and F. L. Crane. 1991. Ceruloplasmin stimulates thymidine incorporation by CCL-39 cells in the absence of serum or growth factors. Biochem. Biophys. Res. Commun. 180:790-796.

7. Alessandri, G., K. Raju, and P. M. Gullino. 1983. Mobilization of capillary endothelium in vitro induced by effectors of angiogenesis in vivo. Cancer Res. 43:1790-1797.

8. Stocks, J., J. M. C. Gutteridge, R. J. Sharp, and T. L. Dormandy. 1974. The inhibition of lipid autoxidation by human serum and its relation to serum proteins and $\alpha$-tocopherol. Clin. Sci. Mol. Med. 47:223-233.

9. Al-Timimi, D. J., and T. L. Dormandy. 1977. The inhibition of lipid autoxidation by human caeruloplasmin. Biochem. J. 168:283-288.

10. Goldstein, I. M., H. B. Kaplan, H. S. Edelson, and G. Weissmann. 1979. Ceruloplasmin. A scavenger of superoxide anion radicals. J. Biol. Chem. 254:4040-4045.

11. Yamashoji, S., and G. Kajimoto. 1983. Antioxidant effect of caeruloplasmin on microsomal lipid peroxidation. FEBS (Fed. Eur. Biochem. Soc.) Lett. 152:168-170.

12. Samokyszyn, V. M., D. M. Miller, D. W. Reif, and S. D. Aust. 1989. Inhibition of superoxide and ferritin-dependent lipid peroxidation by ceruloplasmin. J. Biol. Chem. 264:21-26.

13. Lykens, M. G., W. B. Davis, and E. R. Pacht. 1992. Antioxidant activity of bronchoalveolar lavage fluid in the adult respiratory distress syndrome. Am. J. Physiol. 262:L169-L175.

14. Dormandy, T. L. 1981. Caeruloplasmin: acute-phase antioxidant. Agents Actions. 8:185-197.

15. Gutteridge, J. M. 1985. Inhibition of the Fenton reaction by the protein caeruloplasmin and other copper complexes. Assessment of ferroxidase and radical scavenging activities. Chem. Biol. Interact. 56:113-120.

16. Gutteridge, J. M. C. 1983. Antioxidant properties of caeruloplasmin towards iron- and copper-dependent oxygen radical formation. FEBS (Fed. Eur. Biochem. Soc.) Lett. 157:37-40.

17. Krsek-Staples, J. A., and R. O. Webster. 1993. Ceruloplasmin inhibits carbonyl formation in endogenous cell proteins. Free Radical Biol. \& Med. 14:115-125.

18. Gutteridge, J. M. C., R. Richmond, and B. Halliwell. 1980. Oxygen freeradicals and lipid peroxidation: Inhibition by the protein caeruloplasmin. FEBS (Fed. Eur. Biochem. Soc.) Lett. 112:269-272.

19. Løvstad, R. A. 1982. The protective action of ceruloplasmin on copper ion stimulated lysis of rat erythrocytes. Int. J. Biochem. 14:585-589.

20. Nakano, H., K. Ogita, J. M. Gutteridge, and M. Nakano. 1984. Inhibition by the protein ceruloplasmin of lipid peroxidation stimulated by an $\mathrm{Fe}^{3+}$-ADPadriamycin complex. FEBS (Fed. Eur. Biochem. Soc.) Lett. 166:232-236.

21. Avogaro, P., G. B. Bon, and G. Cazzolato. 1988. Presence of a modified low density lipoprotein in humans. Arteriosclerosis. 8:79-87.

22. Bowry, V. W., K. K. Stanley, and R. Stocker. 1992. High density lipoprotein is the major carrier of lipid hydroperoxides in human blood plasma from fasting donors. Proc. Natl. Acad. Sci. USA. 89:10316-10320.

23. Chisolm, G. M., K. C. Irwin, and M. S. Penn. 1992. Lipoprotein oxidation and lipoprotein-induced cell injury in diabetes. Diabetes. 41:61-66.

24. Salmon, S., C. Mazière, L. Theron, I. Beucler, M. Ayrault Jarrier, S. Goldstein, and J. Polonovski. 1987. Immunological detection of low-density lipoproteins modified by malondialdehyde in vitro or in vivo. Biochim. Biophys. Acta. 920:215-220.

25. Ylä-Herttuala, S. 1991. Macrophages and oxidized low density lipoproteins in the pathogenesis of atherosclerosis. Ann. Med. 23:561-567.

26. Kita, T., Y. Nagano, M. Yokode, K. Ishii, N. Kume, A. Ooshima, H. Yoshida, and C. Kawai. 1987. Probucol prevents the progression of atherosclerosis in Watanabe heritable hyperlipidemic rabbit, an animal model for familial hypercholesterolemia. Proc. Natl. Acad. Sci. USA. 84:5928-5931.

27. Carew, T. W., D. C. Schwenke, and D. Steinberg. 1987. Antiatherogenic effect of probucol unrelated to its hypocholesterolemic effect: evidence that antioxidants in vivo can selectively inhibit low density lipoprotein degradation in macrophage-rich fatty streaks and slow the progression of atherosclerosis in the Watanabe heritable hyperlipidemic rabbit. Proc. Natl. Acad. Sci. USA. 84:77257729.

28. Steinberg, D., and Workshop Participants. 1992. Antioxidants in the prevention of human atherosclerosis: summary of the proceedings of a National Heart, Lung, and Blood Institute workshop: September 5-6, 1991, Bethesda, MD. Circulation. 85:2337-2344.

29. Chisolm, G. M. 1991. Antioxidants and atherosclerosis: a current assessment. Clin. Cardiol. 14:I-25-I-30.

30. Gaziano, J. M., J. E. Manson, P. M. Kidker, J. E. Buring and C. H. Hennekens. 1990. Beta carotene therapy for chronic stable angina. Circulation. 82:201. (Abstr.)

31. Stampfer, J. J., C. H. Hennekens, J. E. Manson, G. A. Colditz, B. Rosner, and W. C. Willett. 1993. Vitamin E consumption and the risk of coronary disease in women. N. Engl. J. Med. 328:1444-1449.

31a. Ehrenwald, E., and P. L. Fox. 1994. Isolation of human ceruloplasmin by chromatographic removal of 9 plasma metalloproteinase. Arch. Biochem. Biophys. 309: in press.

32. Noyer, M., F. E. Dwulet, Y. L. Hao, and F. W. Putnam. 1980. Purification and characterization of undegraded human ceruloplasmin. Anal. Biochem. 102:450-458.

33. Broman, L. 1958. Separation and characterization of two coeruloplasmins from human serum. Nature (Lond.). 182:1655-1657.

34. Sunderman, F. W., and S. Nomoto. 1970. Measurement of human serum ceruloplasmin by its $p$-phenylenediamine oxidase activity. Clin. Chem. 16:903910

35. Rydén, L., and I. Björk. 1976. Reinvestigation of some physicochemical and chemical properties of human ceruloplasmin (ferroxidase). Biochemistry. 15:3411-3417

36. Sato, M., M. L. Schilsky, R. J. Stockert, A. G. Morell, and I. Sternlieb. 1990. Detection of multiple forms of human ceruloplasmin. A novel $M_{\mathrm{r}} 200,000$ form. J. Biol. Chem. 265:2533-2537.

37. Kingston, I. B., B. L. Kingston, and F. W. Putnam. 1977. Chemical evidence that proteolytic cleavage causes the heterogeneity present in human ceruloplasmin preparations. Proc. Natl. Acad. Sci. USA. 74:5377-5381.

38. Takahashi, N., T. L. Ortel, and F. W. Putnam. 1984. Single-chain structure of human ceruloplasmin: the complete amino acid sequence of the whole molecule. Proc. Natl. Acad. Sci. USA. 81:390-394.

39. Laemmli, U. K. 1970. Cleavage of structural proteins during the assembly of the head of bacteriophage T4. Nature (Lond.). 227:680-685.

40. Morel, D. W., P. E. DiCorleto, and G. M. Chisolm. 1984. Endothelial and smooth muscle cells alter low density lipoprotein in vitro by free radical oxidation. Arteriosclerosis. 4:357-364.

41. Kosugi, K., D. W. Morel, P. E. DiCorleto, and G. M. Chisolm. 1987 Toxicity of oxidized low-density lipoprotein to cultured fibroblasts is selective for S phase of the cell cycle. J. Cell. Physiol. 130:311-320.

42. Schuh, J., G. F. Fairclough, and R. H. Haschemeyer. 1978. Oxygen-mediated heterogeneity of apo-low-density lipoprotein. Proc. Natl. Acad. Sci. USA. 75:3173-3177.

43. Esterbauer, H., G. Striegl, H. Puhl, and M. Rothender. 1989. Continuous monitoring of in vitro oxidation of human low density lipoprotein. Free Radical. Res. Commun. 6:67-75.

44. El-Saadani, M., H. Esterbauer, M. El-Sayed, M. Goher, A. Y. Nassar, and G. Jürgens. 1989. A spectrophotometric assay for lipid peroxides in serum lipoproteins using a commercially available reagent. J. Lipid Res. 30:627-630.

45. Steinbrecher, U. P., S. Parthasarathy, D. S. Leake, J. L. Witztum, and D. Steinberg. 1984. Modification of low density lipoprotein by endothelial cells involves lipid peroxidation and degradation of low density lipoprotein phospholipids. Proc. Natl. Acad. Sci. USA. 81:3883-3887.

46. Fox, P. L., G. M. Chisolm, and P. E. DiCorleto. 1987. Lipoprotein-mediated inhibition of endothelial cell production of platelet-derived growth factorlike protein depends on free radical lipid peroxidation. J. Biol. Chem. 262:60466054.

47. Huber, C. T., and E. Frieden. 1970. Substrate activation and the kinetics of ferroxidase. J. Biol. Chem. 245:3973-3978.

48. Kalant, N., and S. McCormick. 1992. Inhibition by serum components of oxidation and collagen-binding of low-density lipoprotein. Biochim. Biophys. Acta. 1128:211-219.

49. Halliwell, B., and J. M. C. Gutteridge. 1986. Oxygen free radicals and iron in relation to biology and medicine: Some problems and concepts. Arch. Biochem. Biophys. 246:501-514.

50. Samokyszyn, V. M., D. M. Miller, D. W. Reif, and S. D. Aust. 1990 Iron-catalyzed lipid peroxidation. In Membrane Lipid Oxidation, vol. 1. C. VigoPelfrey, editor. CRC Press, Inc., Boca Raton, FL. 101-127.

51. Musci, G., M. C. Bonaccorsi di Patti, U. Fagiolo, and L. Calabrese. 1993. Age-related changes in human ceruloplasmin. Evidence for oxidative modifications. J. Biol. Chem. 268:13388-13395.

52. Schilsky, M. L., R. J. Stockert, and J. W. Pollard. 1992. Caeruloplasmin biosynthesis by the human uterus. Biochem. J. 288:657-661. 
53. Sato, M., and J. D. Gitlin. 1991. Mechanisms of copper incorporation during the biosynthesis of human ceruloplasmin. J. Biol. Chem. 266:5128-5134.

54. Morel, D. W., and G. M. Chisolm. 1990. Antioxidant treatment of diabetic rats inhibits lipoprotein oxidation and cytotoxicity. J. Lipid Res. 30:18271833.

55. van Berkel, T. J. C., Y. B. De Rijke, and J. K. Kruijt. 1991. Different fate in vivo of oxidatively modified low density lipoprotein and acetylated low density lipoprotein in rats. Recognition by various scavenger receptors on Kupfer and endothelial liver cells. J. Biol. Chem. 266:2282-2289.

56. Kataoka, M., and M. Tavassoli. 1985. The role of liver endothelium in the binding and uptake of ceruloplasmin: studies with colloidal gold probe. J. Ultrastruct. Res. 90:194-202.

57. Stevens, M. D., R. A. DiSilvestro, and E. D. Harris. 1984. Specific receptor for ceruloplasmin in membrane fragments from aortic and heart tissues. Biochemistry. 23:261-266.

58. Hallböök, T., and H. Hedelin. 1980. Changes in serum copper and serum ceruloplasmin concentration induced by surgical trauma. Acta Chir. Scand. 146:371-373.

59. Fleming, R. E., I. P. Whitman, and J. D. Gitlin. 1991. Induction of ceruloplasmin gene expression in rat lung during inflammation and hyperoxia. Am. $J$. Physiol. 260:L68-L74.

60. Heinecke, J. W., H. Rosen, L. A. Suzuki, and A. Chait. 1987. The role of sulfur-containing amino acids in superoxide production and modification of low density lipoprotein by arterial smooth muscle cells. J. Biol. Chem. 262:1009810103.

61. Cathcart, M. K., A. K. McNally, D. W. Morel, and G. M. Chisolm. 1989 Superoxide anion participation in human monocyte-mediated oxidation of lowdensity lipoprotein and conversion of low-density lipoprotein to a cytotoxin. $J$. Immunol. 142:1963-1969.
62. McNally, A. K., G. M. Chisolm, D. W. Morel, and M. K. Cathcart. 1990. Activated human monocytes oxidize low-density lipoprotein by a lipoxygenasedependent pathway. J. Immunol. 145:254-259.

63. Balla, G., H. S. Jacob, J. W. Eaton, J. D. Belcher, and G. M. Vercellotti. 1991. Hemin: A possible physiological mediator of low density lipoprotein oxidation and endothelial injury. Arterioscler. Thromb. 11:1700-1711.

64. Matsuda, I., T. Pearson, and N. A. Holtzman. 1974. Determination of apoceruloplasmin by radioimmunoassay in nutritional copper deficiency, Menkes' kinky hair syndrome, Wilson's disease, and umbilical cord blood. Pediatr. Res. 8:821-824.

65. Vulpe, C., B. Levinson, S. Whitney, S. Packman, and J. Gitschier. 1993 Isolation of a candidate gene for Menkes disease and evidence that it encodes a copper-transporting ATPase. Nature Genetics. 3:7-13.

66. Klebanoff, S. J. 1992. Bactericidal effect of $\mathrm{Fe}^{2+}$, ceruloplasmin, and phosphate. Arch. Biochem. Biophys. 295:302-308.

67. Belch, J. J., M. Chopra, S. Hutchison, R. Lorimer, R. D. Sturrock, C. D. Forbes, and W. E. Smith. 1989. Free radical pathology in chronic arterial disease. Free Radical Biol. Med. 6:375-378.

68. Kok, F. J., C. M. Van Duijn, A. Hofman, G. B. Van der Voet, F. A. de Wolff, C. H. Paays, and H. A. Valkenburg. 1988. Serum copper and zinc and the risk of death from cancer and cardiovascular disease. Am. J. Epidemiol. 128:352 359.

69. Salonen, J. T., R. Salonen, H. Korpela, S. Suntioinen, and J. Tuomilehto. 1991. Serum copper and the risk of acute myocardial infarction: A prospective population study in men in Eastern Finland. Am. J. Epidemiol. 134:268-276.

70. Reunanen, A., P. Knekt, and R.-K. Aaran. 1992. Serum ceruloplasmin level and the risk of myocardial infarction and stroke. Am. J. Epidemiol. 136:1082-1090. 